\title{
Mechanisms and Outcomes after Crush Injuries of the Foot
}

\author{
Kate Nicholls ${ }^{1 *}$, Henry Goodier ${ }^{2}$, Philippa Bennett ${ }^{1}$, Heath Taylor ${ }^{2}$ and Nicholas Savva ${ }^{1}$ \\ ${ }^{1}$ Dorset County Hospital, Dorchester, United Kingdom \\ ${ }^{2}$ Royal Bournemouth and Christchurch Hospitals NHS Foundation Trust, Bournemouth, United Kingdom
}

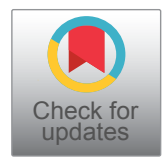

*Corresponding author: Kate Nicholls, Dorset County Hospital, Williams Avenue, Dorchester, DT1 2JY, UK, Tel: 07891309104

\begin{abstract}
Introduction: Crush injuries of the foot are poorly defined in the literature. Previous studies focus on the mechanism of injury or the environment in which they occur. Crush injuries can be associated with long-term sequelae including chronic pain and it has been suggested that seemingly less severe soft tissue injuries can carry significant morbidity equivalent to or worse than bony injuries. The aim of this multicentre study was to provide a contemporary overview of patients presenting with crush injuries to the foot.
\end{abstract}

Methods: A retrospective analysis was performed on data from patients presenting with a crush injury to the foot at three neighbouring district general hospitals between 2008 and 2018. Demographics, mechanism of injury, injuries sustained, management and outcomes at follow-up clinic were recorded.

Results: 152 patients were identified, 88 of which were eligible for inclusion. Crush injuries were seen in an equal proportion of males and females with a median age of 36 (IQR 21-56). Weight drop was the commonest mechanism of injury in almost two thirds (63\%); and $37(42 \%)$ sustained a bony injury, 16 of which (43\%) were open. 19 patients $(22 \%)$ required operative management of their injuries, washout and debridement being the commonest procedure $(7 / 19,37 \%)$. No patient required fasciotomies for compartment syndrome. Twenty three percent of patients reported ongoing problems at follow-up; bony injuries significantly more likely than soft tissue injuries to be associated with morbidity $(p=0.0015)$. The prevailing problem was pain and stiffness $(11 / 20,55 \%)$.

Conclusion: Patients with crush injuries to the foot present a challenging cohort. There is a high rate of reported problems at follow-up, with the predominance of those patients having an underlying bony injury. Early recognition and appropriate management of these injuries is key.

\section{Keywords}

Crush Injuries, Foot, Demographics, Outcomes

\author{
Abbreviations \\ DGH: District General Hospital; ED: Emergency Depart- \\ ment
}

\section{Introduction}

Fractures of the foot account for up to $40 \%$ of lower limb fractures in adults [1], with an incidence of 142 per 100,000 per year [2]. Injuries of the foot and ankle accounted for $6.5 \%$ of all work-place related accidents in the UK in 2019/20 [3]. In addition to isolated injuries, foot injuries can also present as part of polytraumas, where the incidence ranges from $5-13 \%[4,5]$ of all polytrauma patients: they are missed in up to $44 \%$ of cases [6]. Poorer overall functional results are consistently reported in polytrauma patients sustaining foot and ankle injuries compared to those without $[5,7,8]$.

Due to pathophysiological changes, crush injuries of the foot are a specific sub-type of foot trauma and are poorly described in the literature. They have previously been defined as an injury that, "Occurs from an extrinsic or compressive shear force of variable magnitude applied to the foot over a variable period of time" [9]. They are typically the result of heavy falling objects, or motor, railway or industrial accidents [9]. They may present as an isolated injury, or as part of a polytrauma [9].

Crush injuries of the foot and ankle may range in severity from simple soft tissue contusions with no underlying bony injury, to a "mangled extremity" with

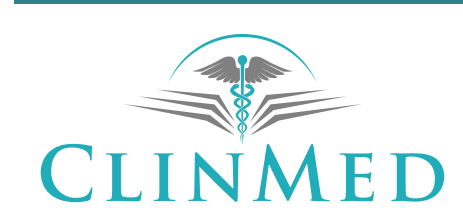

INTERNATIONAL LIBRARY 
multiple fractures, soft tissue disruption, raised intra-compartmental pressures and insensate skin. The appearance of a crushed extremity does not necessarily correlate with injury severity [10], with injuries that appear minor sometimes being associated with major complications [11].

The aim of this study was to characterise the pattern of crush injuries of the foot and ankle presenting to three District General Hospitals (DGH). We aimed to describe the mechanisms through which these injuries are sustained, and the bony and soft tissue consequences of crush injuries.

\section{Methods}

This was a retrospective study conducted at three DGHs on the south coast of the United Kingdom. It was registered with, and approved by, local committees. Cases occurring between 1 January 2008 to 31 December 2018 were identified by three mechanisms:

1. Local Emergency Department (ED) electronic patient record systems coded as a crush injury to the foot, ankle or leg;

2. Electronic radiographic software was searched for radiographs of the foot, calcaneum and ankle where the request detailed a crush mechanism;

3. Records of fracture clinic attendances were searched for patients referred following injury of their foot or ankle, and clinic letters reviewed to identify the mechanism of injury.

Patients of any age were included if they had a crushing injury at or distal to the level of the malleoli of the ankle. Both soft tissue and bony injuries were included. Crush injuries were counted as those where medical notes stated or described a crushing force through one of four mechanisms:

1. Weight being dropped onto the foot;

2. Runover by vehicle;

3. Stamped on by person or animal;

4. Caught between or under an object.

Data was gathered on patient demographics, mechanism of injury and injuries sustained. Further details on management were obtained from electronic hospital records. Initial outcomes were determined from orthopaedic follow-up clinics.

\section{Statistical analysis}

Descriptive data are presented as medians with interquartile ranges (IQRs). Fisher's exact test was used for comparison of dichotomous data. A threshold for significance was set at $p<0.05$.

\section{Results}

A yearly average of 24807 patients presented to one DGH emergency department, of which 2687 patient's
Table 1: Patient demographics.

\begin{tabular}{|l|l|}
\hline \multicolumn{2}{|l|}{ Demographics (n= 88) } \\
\hline Sex n (\%) & $44(50)$ \\
\hline Male & $44(50)$ \\
\hline Female & \\
\hline Age (years) & 36 \\
\hline Median & $21-56$ \\
\hline IQR & \\
\hline A\&E Attendance, $\mathbf{n}(\%)$ & $74(84)$ \\
\hline Ambulant & $14(16)$ \\
\hline Ambulance & \\
\hline Mechanism of Injury, $\mathbf{n}$ (\%) & $55(63)$ \\
\hline Weight drop & $12(14)$ \\
\hline Runover by vehicle & $12(14)$ \\
\hline Stamped on by person or animal & $9(10)$ \\
\hline Caught between or under an object & \\
\hline Injuries & $37(42)$ \\
\hline Fracture & 30 \\
\hline Forefoot & 10 \\
\hline Midfoot & 3 \\
\hline Hindfoot & $51(58)$ \\
\hline Soft Tissue only & \\
\hline
\end{tabular}

"Total of fractures exceeds 37 due to patients presenting with fractures to multiple regions of foot.

chief complaint was an orthopaedic injury. Further detail on emergency department attendances from the other two DGHs was not provided.

There were 152 patients identified during the study period, $1^{\text {st }}$ January 2008 and $31^{\text {st }}$ December 2018 , across all three DGH's of which 88 were eligible for inclusion. The commonest reason for exclusion was a mechanism describing a fall from height, rather than a crush injury (25/64, 39\%). The median patient age was 36 years (IQR 21-56); 44 (50\%) were male. The commonest mechanism of injury was weight drop $(n=55,63 \%)$ with further detail given in Table 1.

The majority of patients $(51 / 88,58 \%)$ suffered soft tissue damage only following crush injury. Of the 37 patients with fractures, six had injuries in multiple regions of the foot. Sixteen patients (16/37 (43\%), 16/88 (18\%)) had open fractures, of whom $13(13 / 16,81 \%)$ received antibiotics in the Emergency Department. A tetanus booster was given to eight patients $(8 / 16,50 \%)$.

Of the 88 patients included in this study, $40(40 / 88$, $45 \%)$ were discharged directly from ED with no further follow-up planned, and $8(8 / 88,9 \%)$ were discharged from ED with outpatient follow-up booked. Forty patients (40/88, 45\%) required Trauma \& Orthopaedic review in ED: of these $2(2 / 40,5 \%)$ required no further follow-up, $9(9 / 40,23 \%)$ were discharged with further review in outpatient clinic booked, and 29 (29/88, 33\%) required admission into hospital. 
A total of 19 patients $(19 / 88,22 \%)$ required operative management of their injuries: no patient required fasciotomies for compartment syndrome. Nine patients ( $9 / 37$, 24\%) underwent operative fixation of their fractures, with further detail shown in Table 2. No patient required amputation following the crush injury to their foot.

\section{Outcomes}

Ongoing symptoms at orthopaedic follow-up clinics were recorded and split into four categories: Pain and stiffness, non-union, infection and hypoesthesia. The median follow-up time for was 1 month (IQR 1-2.5 months).

Three patients were discharged without follow-up after inpatient admission, thus a total of 43 patients $(43 / 88,49 \%)$ were followed-up in outpatient clinic. Upon clinical review, 20 patients $(20 / 88,23 \%)$ were noted to have ongoing symptoms. Eleven patients (11/20 (55\%), $11 / 88(13 \%))$ complained of ongoing pain and stiffness at the time of discharge. Four patients $(4 / 20(20 \%), 4 / 88$ (5\%)) developed infection requiring antibiotics: Two of these were following soft-tissue procedures, one was following fracture fixation using k-wires, and one infection occurred in a patient with a soft tissue injury managed non-operatively. Three patients (3/20 (15\%), 3/88 (3\%)) experienced delayed union of their metatarsal fractures: one patient was a smoker, and the fracture finally united with non-operative management following extended immobilisation in a boot. Two patients $(2 / 20$ $(10 \%), 2 / 88(2 \%))$ complained of persistent hypoes-

Table 2: Operative management of crush injuries.

\begin{tabular}{|l|l|}
\hline Operative Management $(\mathbf{n}=\mathbf{1 9})$ & \\
\hline Operation performed, $\mathbf{n}(\%)$ & $7(37)$ \\
\hline Washout, debridement, exploration & $3(16)$ \\
\hline Nail bed repair & $4(21)$ \\
\hline Percutaneous K-wire fracture fixation & $5(26)$ \\
\hline Open reduction internal fixation of fracture & \\
\hline
\end{tabular}

thesia. Two patients remained under follow-up for 18 months, with the longest follow-up recorded being 21 months for a patient with ongoing pain and stiffness.

The likelihood of patients complaining of ongoing symptoms was not related to the mechanism of injury $(p=0.43)$, with detail provided in Table 3. Patients were significantly more likely to complain of ongoing symptoms if they had a bony injury, compared to those with soft tissue only injuries $(p=0.0015)$. Twelve patients sustaining fractures complained of ongoing symptoms. Only three patients with soft tissue injuries described ongoing symptoms: One sustained a nailbed injury of their great toe following a weight drop. This required washout and debridement and subsequently developed infection. One patient sustained a purely ligamentous LisFranc injury managed non-operatively, and the final patient sustained a weight drop resulting in bruising over the dorsum of the foot which required a nerve block in fracture clinic.

\section{Discussion}

This study characterises crush injuries of the foot presenting to three District General Hospitals over a tenyear period. It describes the injuries seen and their management. Crush injuries of the foot are an uncommon presentation to the Emergency Department. Weight drop onto the foot was the commonest mechanism of injury, with the majority of patients suffering soft-tissue damage only. Despite crush injuries being uncommon, a third of patients required admission to hospital, and nearly a quarter required operative management of their injuries. Upon final review in outpatient clinic, nearly a quarter were complaining of ongoing problems with the foot, indicating that despite their rarity, these injuries have the potential to carry a substantial morbidity and burden to regional orthopaedic departments. Patients suffering bony injuries following a crushing mechanism were significantly more likely to complain of ongoing problems that those with soft tissue only injuries.

Table 3: Occurrence of complications based on injury location and mechanism.

\begin{tabular}{|c|c|c|c|c|}
\hline & $\begin{array}{l}\text { Infection } \\
(n=4)\end{array}$ & $\begin{array}{l}\text { Delayed union } \\
(n=3)\end{array}$ & $\begin{array}{l}\text { Pain or stiffness } \\
(n=11)\end{array}$ & $\begin{array}{l}\text { Hypoesthesia } \\
(n=2)\end{array}$ \\
\hline \multicolumn{5}{|l|}{ Injury location } \\
\hline Hindfoot & & & 2 & \\
\hline Midfoot & & & 5 & \\
\hline Forefoot & 3 & 3 & 3 & 2 \\
\hline Midfoot and forefoot & 1 & & & \\
\hline Midfoot and hindfoot & & & 1 & \\
\hline \multicolumn{5}{|l|}{ Mechanism of injury } \\
\hline Weight drop $(n=55)$ & 4 & 2 & 4 & 1 \\
\hline Runover $(n=12)$ & & 1 & 4 & \\
\hline Stamped on $(n=12)$ & & & 2 & \\
\hline Caught between objects $(n=9)$ & & & 1 & 1 \\
\hline
\end{tabular}


Descriptions of crush foot injuries in the literature remain rare. Previous descriptions have focused on specific mechanisms of injury [12,13], broad descriptions of anatomical considerations and treatment [14], or group crush injuries together with all forms of complex foot injury [15]. Outcomes are similarly poorly defined, though one group has previously noted that up to $50 \%$ of patients required ambulation assistance following a crush mechanism [16]. This has prompted the publication of detailed management protocols for these injuries, in recognition of the unique pathophysiology of crush mechanisms $[11,15]$.

Defining which injuries count as occurring via a crushing mechanism presents its own problems. Definitions vary, and include, "the result of a body part being forcibly compressed between two hard surfaces" [15], an "injury that occurs from an extrinsic compressive or shear force of variable magnitude applied to the foot over a variable time period" [11], and "direct physical trauma to the torso, extremities or other parts of the body from an external crushing force" [16]. This compression can cause ischaemia and swelling, and subsequent reperfusion injury can result in a secondary insult from cellular death, rhabdomyolosis and compartment syndrome $[15,17]$.

The initial subcategorization of mechanism of crush foot injuries in 1994 was described as heavy falling objects or motor, industrial, or railway vehicles rolling over or crushing the foot [9]; and thus is not as applicable now due to the reduction in use of industrial and railway industries. Highlighted in this study are four broad categories which are felt to be more appropriate for categorisation of mechanism of injury: Weight drop by heavy falling objects, foot runover by motor or industrial vehicles, foot stamped on by humans or animals or foot caught between two objects. Although advantageous to know the mechanism of injury, this study in agreement with previous studies notes that no correlation exists between mechanism of injury and outcome and therefore treatment should not be determined based on the mechanism of injury [9].

There are obvious weaknesses to this study. Its retrospective design means injuries not coded as occurring via a crushing mechanism on presentation to ED might have been missed. Similarly, no standardised time points for follow-up in clinic existed, and our follow-up times are consequently relatively short. Due to the rarity of the injury, we present relatively small numbers to draw conclusions from.

\section{Conclusion}

Despite this, we present an up-to-date description of crushed foot injuries presenting to three district general hospitals, adding to the paucity of literature in this area. Patients with crush injuries of the foot and ankle present a broad and challenging cohort and a substantial num- ber describe ongoing problems at follow-up. It is therefore vital that the clinician is alert to the possibility of a crush injury to the foot or ankle and can appropriately tailor the treatment and rehabilitation and manage the patient's expectations accordingly.

\section{Acknowledgements}

No conflict of interest to be declared.

\section{Sources of Support (If Applicable)}

Disclosure of funding received for this work from any of the following organizations: National Institutes of Health (NIH); Wellcome Trust; and other(s).

This research received no specific grant from any funding agency in the public, commercial, or not for profit sectors.

\section{Statement of Equal Authors' Contribution}

$\mathrm{KN}$ and HG collected and carried out data analysis and obtained informed patient consent. $\mathrm{KN}$ wrote the first draft of the manuscript. All authors reviewed and edited the manuscript and approved the final version of the manuscript.

\section{References}

1. Court Brown CM, Caesar B (2006) Epidemiology of adult fractures: A review. Injury 37: 691-700.

2. Jorgensen SBRC. Incidence and Epidemiology of Foot Fractures.

3. (2019) Reporting of Injuries, Diseases and Dangerous Occurences Regulations.

4. Banerjee $M$, Bouillon $B$, Shafizadeh $S$, Paffrath $T$, Lefering $\mathrm{R}$, et al. (2013) Epidemiology of extremity injuries in multiple trauma patients. Injury 44: 1015-1021.

5. Probst $C$, Richter M, Lefering R, Frink M, Gaulke R, et al. (2010) Incidence and significance of injuries to the foot and ankle in polytrauma patients-An analysis of the Trauma Registry of DGU. Injury 41: 210-215.

6. Ahrberg AB, Leimcke $B$, Tiemann AH, Josten $C$, Fakler JKM (2014) Missed foot fractures in polytrauma patients: A retrospective cohort study. Patient Saf Surg 8: 10.

7. Tran T, Thordarson D (2002) Functional outcome of multiply injured patients with associated foot injury. Foot Ankle Int 23: 340-343.

8. Schemitsch EH, Waddell JP, McKee MD, Turchin D (1999) Do foot injuries significantly affect the functional outcome of multiply injured patients? Journal of Orthopaedic Trauma 13: 1-4.

9. Myerson MS, McGarvey WC, Henderson MR, Hakim J (1994) Morbidity after crush injuries to the foot. Journal of Orthopaedic Trauma 8: 343-349.

10. Posch Jl, Weller Cn (1954) Mangle and severe wringer injuries of the hand in children. J Bone Joint Surg Am 36: 57-63.

11. Vora A, Myerson MS (2002) Crush injuries of the foot in the industrial setting. Foot and Ankle Clin 7: 367-383.

12. Hong CC, Nashi N, Kuan WS, Teh JWD, Tan KJ (2015) Forklift-related crush injuries of the foot and ankle. Foot Ankle Int 36: 806-811. 
13. Jeffers RF, Boon Tan H, Nicolopoulos C, Kamath R, Giannoudis PV (2004) Prevalence and patterns of foot injuries following motorcycle trauma. J Orthop Trauma 18: 87-91.

14. DiDomenico LA, Thomas ZM (2014) Midfoot crush injuries. Clinics in Podiatric Medicine and Surgery 31: 493-508.

15. Schepers T, Rammelt S (2017) Complex Foot Injury: Early

and Definite Management. Foot and Ankle Clinics 22: 193213.
16. Omer GE, Pomerantz GM (1972) Initial Management of severe open injuries and traumatic amputations of the foot. Arch Surg 105: 696-698.

17. Godat L, Doucet J (2019) Severe crush injury in adults. UpToDate. 